\title{
Aspects on Anaerobic Digestion of Municipal Sludge, Some Aspects on its Sustainability and Possible Enhancements
}

\author{
Stig Morling \\ Sweco Environment and affiliated to Royal Institute of Technology (KTH), Stockholm, Sweden
}

Email address:

stig.morling@sweco.se

To cite this article:

Stig Morling. Aspects on Anaerobic Digestion of Municipal Sludge, Some Aspects on its Sustainability and Possible Enhancements. Journal of Water Resources and Ocean Science. Vol. 8, No. 2, 2019, pp. 21-27. doi: 10.11648/j.wros.20190802.12

Received: April 8, 2019; Accepted: May 23, 2019; Published: June 10, 2019

\begin{abstract}
The anaerobic treatment of organic rich pollutants has a very long history within the water industry. Two major applications have been used: Treating sludge streams from midsized and large wastewater treatment plants and for industrial wastewater streams containing high concentrations of organic carbon. This paper presents the status of anaerobic digestion of sludge streams in municipal wastewater. The paper highlights both the potentials and limitations of the technology. Further the alternative or complementing HTC-technology is presented and analyzed. The constraints, limitations and options for the reuse of processed municipal sludge is accordingly pointed out. Our usage of water is found more and more complex, along with the addition of a number of synthetic agents, such as pharmaceuticals and other complex polluting agents we find that the traditionally acknowledged sludge treatment stabilization methods are not sufficient. The paper points out that the anaerobic digestion may be combined with for instance the HTC-process. In a longer perspective the HTC may even replace the current anaerobic digestion. However, the HTC-technology will raise further interesting questions: The important points that need further investigations are inter alia: 1) To further clarify the quality of reject water from the hydrochar, with respect to rest pollutants. 2) To evaluate to what extent the HTC process may become a feasible way to disintegrate pharmaceutical remains found in municipal sludge. 3) How to further enhance the ways to recover raw materials from the hydrochar, such as phosphorus and carbon. Nethertheless, the process may allow for some very promising pathways within the future municipal sludge management.
\end{abstract}

Keywords: Sludge Digestion, Solids Retention Time, Primary Sludge, Waste Activated Sludge, SRT, Biogas Gas Production, HTC, Carbon, Phosphorus Recovery

\section{Background}

The anaerobic digestion of municipal sludge is by convention based on natural processes found in nature. Wastewater management has been developed to a very high extent based on the conviction that a sustainable path for wastewater and sludge treatment is to mimic the processes found around us. What we try to do is to accelerate the processes by different ways to optimize the driving forces. The anaerobic digestion is in this respect a typical example. As a matter of fact, the concept of anaerobic decomposition was established in science dealing with water treatment more than 100 years ago. Early examples of anaerobic digestion are found especially within European countries, either as decentralized small "septic tanks", anaerobic ponds or as separate sludge reactors at larger plants. Early typical large anaerobic digesters were built during the 1930s for instance in Stockholm, the capital of Stockholm. The updated and modernized plants are to a large extent still based on the early technological concept.

The initial reasons for the use of sludge treatment with anaerobic digestion maybe summarized as follows:

(1) To combat and control odors from raw sludge;

(2) To limit the sludge production;

(3) To establish an accepted sludge stabilization;

(4) To use the digested sludge as a fertilizer in farmland areas.

Today many anaerobic digesters are found all around the 
world serving many cities and towns. In Figure 1 a photo of a large facility serving the city of Eskisehir in Turkey is shown. The facility was put into operation in year 2011.

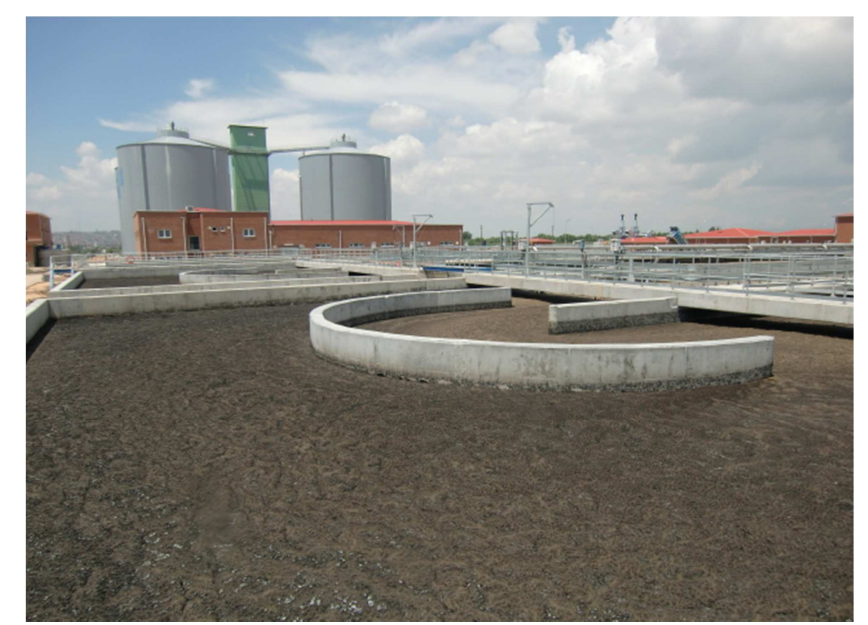

Figure 1. Anaerobic digesters at the WWTP of Eskisehir, sized for more than 660000 -person equivalents.

\section{Anaerobic Digestion, Traditional and Newer Applications}

The anaerobic digestion maybe performed principally at three temperature levels:

(1) Thermophilic digestion at a temperature of $50-57^{\circ} \mathrm{C}$;

(2) Mesophilic digestion at a temperature of $37^{\circ} \mathrm{C}$;

(3) Psycrophilic digestion at low temperatures $<15^{\circ} \mathrm{C}$.

The dominant model so far has been the mesophilic model worldwide. However, a development towards the thermophilic model has taken place during the last 30 to 40 years, especially at larger plants.

The fundamental biological process that occurs in the anaerobic process maybe - very simplified - be characterized by the following phases:

(1) A hydrolysis and acidification stage, when organic compounds are released by a transformation into organic acids, such as proprion and acetate. This reaction stage performs under acidic conditions, and may inhibit the following process stage, unless the process will adjust to a higher $\mathrm{pH}$ level. During startup of an anaerobic digestor it is normally imperative to add alkaline compounds to the sludge.

(2) A gasification phase when the acids are converted into gases such as $\mathrm{CO}_{2}$ and $\mathrm{CH}_{4}$. Once the gasification stage is established the $\mathrm{pH}$-adjustment of the process will continue without any further external alkaline addition.

The anaerobic processes that occur are indeed complex and will also cause other reactions. The content of sulphates in the transportation water will be reduced to $\mathrm{H}_{2} \mathrm{~S}$. This conversion may promote a precipitation metal of sulphides. The anaerobic process will also hydrolyze organic nitrogen bound in the sludge into ammonia nitrogen.

The interest for the anaerobic digestion has grown in the latest decades, thanks to its energy potential. The methane gas is seen as a valuable energy form to be recovered. The traditional way has been to use this energy for internal needs, within the wastewater treatment facility itself. By converting the gas into heat and electricity the operation of some of the wastewater treatment plants could be operated with a minor external supply of energy. Such an example was the modernization of a medium sized Swedish WWTP (capacity 40000 person equivalent), serving the town of Sandviken. By adopting an advanced chemical precipitation model followed by a final filtration step for the wastewater treatment the amounts of sludge containing organics increased at the plant. The conversion of the sludge stabilization process was done by going from quick lime addition into mesophilic digestion. This resulted in a production of methane gas that the daily amounts were enough to provide a self-supply of energy for the plant, covering both the needed electrical supply for process units and the major part of the heating demands.

\section{Anaerobic Digestion, a Model for Energy Recovery}

The overall carbon balance over a mesophilic digestion is illustrated in Figure 2

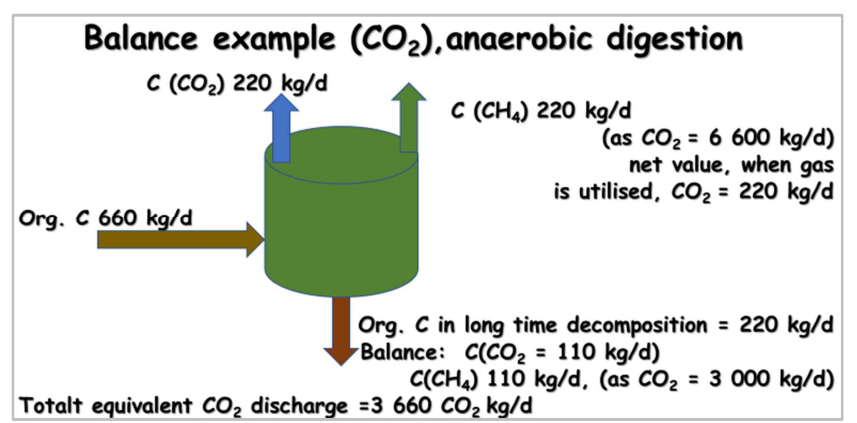

Figure 2. Typical carbon balance over a mesophilic digestion, with conversion figures on carbon dioxide and methane gas inserted.

As seen from the figure, around $1 / 3^{\text {rd }}$ of the inlet organic carbon is converted into methane gas within the anaerobic process itself, and thereby possible to utilize for energy production. The remaining $2 / 3^{\text {rd }}$ of the inlet carbon will directly end up in carbon dioxide or be stored in the digested sludge. This deposit of sludge will however in a longer perspective result in a conversion of organic carbon into carbon dioxide and methane gas, thus a further addition to the atmospheric $\mathrm{CO}_{2}$ load.

The specific methane gas production from one $\mathrm{kg}$ of organic matter is around $1 \mathrm{Nm}^{3}$. In turn the gas energy content is around $5-6 \mathrm{~kW} / \mathrm{Nm}^{3}$. Finally, the conversion in turn into electricity will be between 35 and up to $40 \%$ of the energy content in the gas. The heat from the gas engine is normally used for heating the raw sludge by means of heat exchangers. The surplus heat maybe used for heating the technical buildings and control facilities.

However, with the new focus on the "fossil combat", the interest in "biogas" has got a new perspective. The further 
refining of the "biogas" to be used for buses and cars has become a very popular alternative for the use of gas. This model is promoted as an example of a "circular resource use"!

The main critical issue in relation to the rest product, the separated sludge will be discussed in the following chapter, along with some other issues. A special circumstance found at some treatment plants with anaerobic digestion is the spontaneous precipitation of struvite in the reject water from the mechanical dewatering of the sludge. This matter is further discussed below.

\section{Some Critical Aspects on the Anaerobic Digestion in View of New Insights}

As already presented the anaerobic digestion applied for municipal sludge processing has been established early in the modern wastewater business. In this perspective it is not at all surprising that the technology has undergone developments as well as being questioned. In this chapter, some crucial points regarding the technology are highlighted.

\subsection{Methane Gas Production Versus Extended Aeration of Biological Excess Sludge}

The development of advanced biological nitrogen removal has put focus on the available organic carbon in municipal wastewater. As the nitrogen removal process needs organic carbon for the denitrification stage this in turn means a "competition" between two process stages in a modern wastewater treatment plant. On one side the carbon needs for denitrification, and on the other side the conversion of organic carbon found in the wasted activated sludge into methane gas in the anaerobic digestion process. This new situation was the starting point for a study conducted by the Lund Technical University in co-operation with Sweco Environment, see [1]. The critical question put was the following: To what extent does the nitrogen removal stage affect the methane gas potential found in the waste activated sludge? Sludge from one of the major Swedish treatment plants, the Sjölunda WWTP, serving the city of Malmö in the southern part of Sweden was used for testing. By simulating different aerobic solids retention times (SRT) for the excess sludge a very clear relation was found. Figure 3 presents the results. The figure clearly illustrates the difference between a waste activated sludge with an SRT of 2 days, and sludges representing typical extended aeration models, with a span of aerated SRTs from 10 days to 20 days. The used anaerobic digestion time was 10 days for all sludge samples. For the short time SRT (2 days) case a potential methane gas formation expressed as Biochemical Methane Potential (BMP) is found at $300 \mathrm{Nml} / \mathrm{g}$ VSS. This result is compared with the results for different samples with extended aeration times that ended up in a potential of $<100 \mathrm{Nml} / \mathrm{g} \mathrm{VSS}$. Further evidence of the change of the waste activated sludge organic content is presented in Table 1. The ratio VS/TS decreased from a level of 0.72 to around $0.64: 1$, as the aerated time is increased from 2 days to 20 days. It would be observed that the major impact is reached even at an extended aeration time of 10 days.

Table 1. TS and VS content of activated sludge from Sjölunda WWTP after thickening.

\begin{tabular}{llll}
\hline Activated sludge & TS (\%) & VS (\%) & VS/TS \\
\hline Activated sludge (3) & 1.07 & 0.77 & 0.72 \\
10d-SRT extra aerated sludge & 0.71 & 0.45 & 0.64 \\
12d-SRT extra aerated sludge & 0.80 & 0.51 & 0.64 \\
16d-SRT extra aerated sludge & 1.1 & 0.71 & 0.64 \\
20d-SRT extra aerated sludge & 0.90 & 0.57 & 0.62 \\
\hline
\end{tabular}

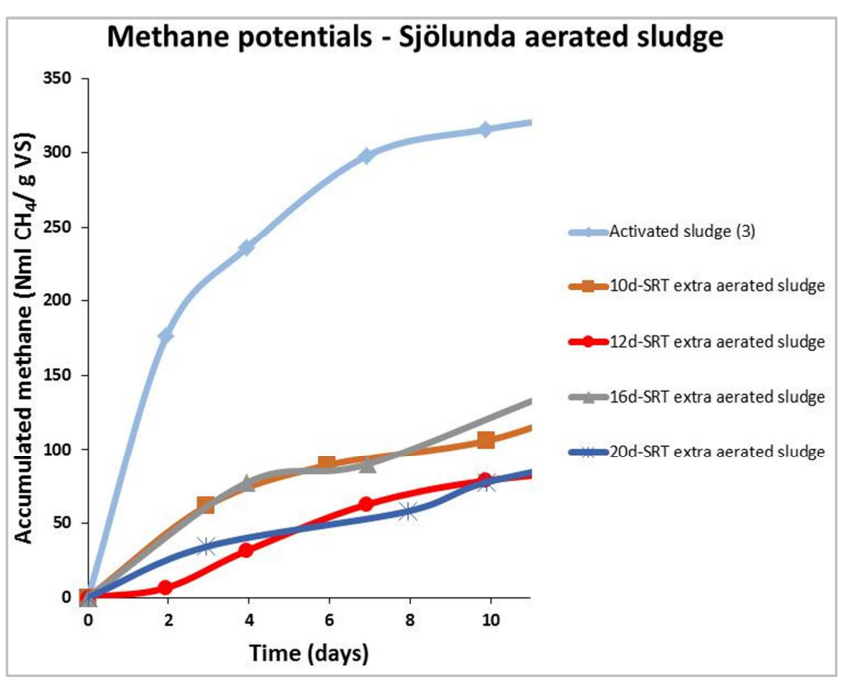

Figure 3. Relation between digestion time and accumulated methane gas production related to different extra aerated Solids Retention Times (SRT) in the activated sludge reactor.

Based on these results some critical questions were raised:

The negative internal process consequences are sometimes underestimated in municipal sludge management in relation to waste activated sludge and the anaerobic digestion process.

The amount of easily available organic carbon for gas production is limited in biologically wasted sludge with extended aeration time. This in turn results in that the potential in waste activated sludge with an extended SRT as an energy source maybe questioned.

The findings in the presented study has also been a subject in other contemporary studies. In 2013 a technical paper presented the importance of a limited SRT in the activated sludge process, see Batstone and Keller, reference [2]. They found a clear relation with the BMP level and the aerated SRT in the waste activated sludge from a SBR reactor. They stated also that the thermophilic digestion would increase the BMP production, quote: "Anaerobic degradability of the sludge generated in the high-rate SBR process was strongly linked to SRT, with measured degradability extent being $85 \%$ (2 days SRT), 73\% (3 days), and 63\% (4 days), but it was not influenced by digestion temperature. However, the rate of degradation for 3 and 4 days SRT sludge was increased by $45 \%$ at thermophilic conditions compared to mesophilic 


\section{conditions.}

Further findings from a Doctoral Thesis, presented by My Carlsson in 2013, see [3]. Generally this thesis supports the findings discussed above. A figure presented in the thesis demonstrates this (Figure 5, page 15 in the thesis). Carlsson also underlines the almost classical problem of going from the laboratory scale to the implementation in full scale. The actual findings in a well-controlled test would always be addressed with an open and critical mind.

Another side-effect often overlooked is the anaerobic hydrolysis of organically bound nitrogen and phosphorus in the sludge. As an internal (additional) pollution load on a wastewater treatment plant this matter maybe found important. Experiences from large plants indicates especially an internal nitrogen load - mainly as ammonia nitrogen $\left(\mathrm{NH}_{4}-\mathrm{N}\right)$ - which may be as high as 20 to $25 \%$ of the total nitrogen load on the biological stage.

Further observed process complications with respect to an anaerobic digestion of both primary sludge and waste activated sludge rich in nutrient has been defined as (in this perspective an unwanted) struvite formation. This in turn has caused operation problems of downstream dewatering process, as the struvite crystallization $\left(\mathrm{NH}_{4} \mathrm{MgPO}_{4} \cdot 6 \mathrm{H}_{2} \mathrm{O}\right)$ may clog reject pipes within the plant.

\subsection{More Stringent Requirements on the Sludge Treatment}

The endlessly sharpening of sludge quality demands maybe a result of both more complex polluting agents found in the sludge and the needs for reusing the wanted properties in the sludge. For a long time use of different sludge streams aimed especially for the use of humus, (organic carbon) and nutrients, mainly phosphorus and nitrogen. The first well known sludge quality problem in this respect was the heavy metal content found in sludge, especially $\mathrm{Cd}$ (Cadmium), $\mathrm{Hg}$ (Mercury), $\mathrm{Pb}$ (led) $\mathrm{Cr}$ (Chromium) and $\mathrm{Cu}$ (Copper). This matter has been mitigated to a significant extend in some countries mainly by a systematic "up-stream" work, combined with more stringent law restrictions and strict quality control of added precipitant agents.

In many countries' strict regulatory conditions on sludge stabilization and hygienization have been implemented. This has often resulted in a separate hygienization reactor treating the sludge in a batch mode for 2 to 4 hours at an elevated temperature $>70-80^{\circ} \mathrm{C}$.

In 2017 the German Environmental Agency [4] presented a highly critical study on the high risk condition of digested sludge. The crucial concern presented, being relevant especially in the industrial countries is that now revolving around pharmaceutical remains in the sludge stream. The more specific point is the risk that these remains in turn will promote the multi-resistant bacteria in the fertile soil. The study points out the only possible final treatment for the sludge is a mono incineration.

As a summary, would these new demands necessarily mean the end of anaerobic digestion?

Taking into consideration that the technical lifetime for an anaerobic digestion installation is 15 to 25 years this question may be raised. Many examples maybe presented from the market. However, at the end of the lifetime the normal solution is to renovate or upgrade the installations. Then the question arises: Will an anaerobic digestion after an upgrade be possible to combine with further, refined technologies? Some initial promising pathways are presented in the following chapter.

\subsection{Demands on Reuse of Carbon and Phosphorus in Municipal Sludge}

The rapidly changing industrialized world will create additional demands and thereby also a possible prolongation of the anaerobic digestion process. As pointed out the demands for carbon and phosphorus as renewable resources are important today.

The need to extract more carbon as methane gas may become an attractive model. The demands for phosphorus recovery are becoming even more urgent. The high-quality superphosphate sources are soon exhausted. The dominance of super-phosphate with higher contents of polluting heavy metals, i.e. $\mathrm{Cd}$ and similar compounds may become the main available source, thus in turn calling for either more refined technology for these superphosphate resources or calling for other pathways to find "cleaner" phosphates.

This in turn has raised the interest to recover phosphorus from municipal sludge. One model maybe to extract struvite from the wastewater process, either by means of enhanced water processes or by a direct handling of the sludge. The water industry market has some competing companies for struvite production.

Another way to enhance phosphorous removal at the wastewater treatment plant maybe found in the so called "Phostrip Process". The basis for the process model is a development of the anaerobic/aerobic model for activated sludge. This process may allow for a separate phosphorousrich side stream, Figure 4 illustrates the principal flow sheet model. For further information regarding this process scheme, see [5].

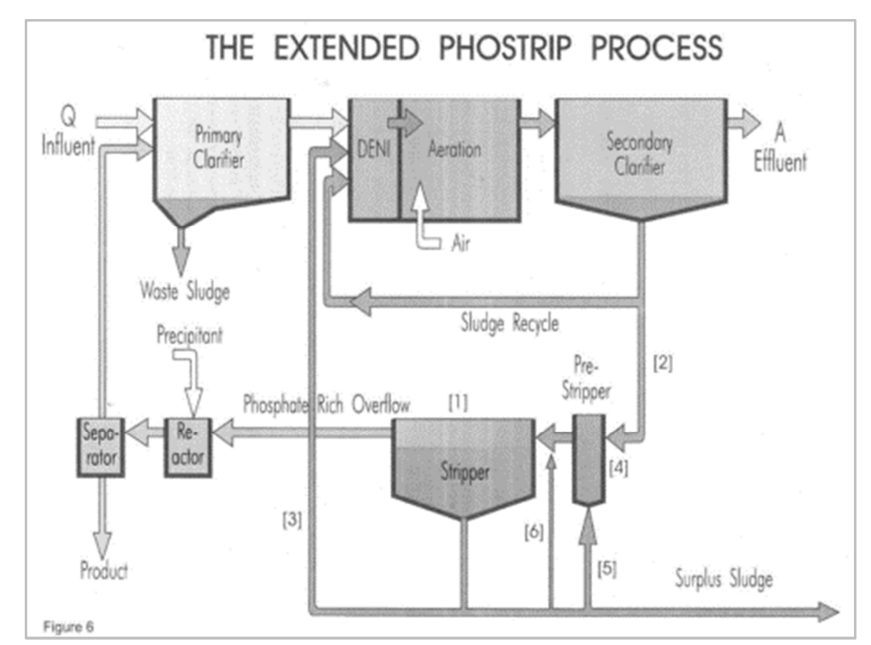

Figure 4. Principal flow sheet for the Phostrip Process. 


\subsection{The Hydrothermal Carbonization (HTC) Process Development}

An alternative for sludge treatment is represented by the development of the Hydro Thermal Carbonization (HTC) process. The process has been developed during the last three decades. The contemporary research work was initiated by professor Marcus Antonietti at the Max Planck University. A very comprehensive presentation of the HTC process and its developments is found in reference [6]. The HTC process is characterized as follows:

Organic rich matters, such as municipal sludge, or other wastes with rich content of carbon, are suitable for the HTC treatment. The process could be operated in a batch mode, a semi-batch mode, or arranged in a continuous plug-flow reactor, by observing the following process conditions:

(1) Operating process temperature $190-230^{\circ} \mathrm{C}$;

(2) Operation pressure up to 20 bars;

(3) Efficient reaction time $2-8$ hours, related to the raw material quality.

(4) The inlet solids concentration should be $>10$ to $20 \%$ DS, to establish feasible conditions.

Findings so far from many test studies are given in, for instance [7] that provides fundamental analysis of the process. Further tests are presented in [8] through to [10]. Of special interest in this perspective are the studies regarding the potential to combine the mesophilic digestion with the HTC-process and to recycle the process water to the digestion. As a conclusion of this process option the report concludes as follows, see [10], quote:

"Shortly, the principle of the process is that $0.2 \mathrm{~m}^{3}$ of the HTC process water is added to $1 \mathrm{~m}^{3}$ of digested sewage sludge giving a total influent flow to the digester of $1.2 \mathrm{~m}^{3}$. The effluent from the digester is concentrated to $10 \%$ DS and hydrothermally carbonized. The produced HTC slurry is separated into hydrochar and $0.2 \mathrm{~m}^{3}$ process water and the loop starts again. Based on the obtained results in this study, the increased methane yield from the process can be estimated to $30 \%$."

These findings are further confirmed in a work presented as a Master thesis in 2017, see [11]. The study aimed to demonstrate that the recirculation of process water from the HTC back to the anaerobic digestion would enhance the methane gas production. In laboratory tests very similar to the tests performed at the Lund Technical University [1] by studying the BMP. The findings in the Master Study shows clearly that the recycled process water has got a BMP almost identical to the BMP-value found for primary sludge at a municipal plant. The presented curves with respect to the BMP development for all three tested samples, the primary sludge, the Biochar and the process water from the HTC process are striking in some important respects:

(1) The primary sludge BMP development is very similar to the findings for the activated sludge with a very short time SRT at the Sjölunda WWTP, see Figure 3 above, and Figure 5 below;

(2) The biochar BMP development comparable with an activated sludge with very extended SRT;

(3) The filtered process water from the HTC process shows a BMP scheme almost identical to the primary sludge scheme.

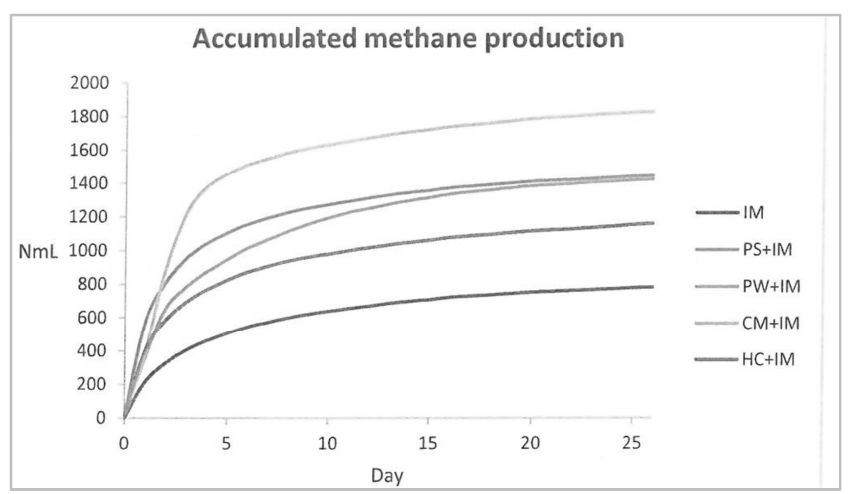

Figure 5. Results from BMP performed by Nilsson, E., [ref 11] regarding different organic polluted streams in relation to anaerobic digestion and HTC.

Further, the findings in the study [11] shows that the recycle stream of process water from the HTC-process does not carry any inhibitors (toxic matters) for the anaerobic digestion process.

This in turn points out a further step for the enhancement of the mesophilic process, however, the question of the impurities may remain, such as heavy metals bound in the hydrochar and the question of complex organic compounds.

Although the HTC technology seems to include promising and attractive options, there are still important questions to be raised and clarified in further studies. Recently newly added knowledge on the HTC-process options are revealed by Ducey and Ro. (2019), see reference [12]. They studied the effects of the HTC-process in relation to specific impurities in manure from cows and other farm-animals. They state with respect to the traditional biological treatment methods, such as anaerobic digestion or composting of organic matters the following: "Along with pathogen reduction, the fate of microbial DNA after treatment remains an area of active research. While these treatments (anaerobic digestion or composting) may be enough to kill pathogens, their ability to degrade DNA to the point where the genetic information encoded is unusable remains a poorly studied area. This raises the potential of significant amounts of cell-free, microbially-derived DNA carrying pathogen factors such as antibiotic resistance genes (ARGs), being introduced to agricultural environments, or into public lands." The statement is well in line with the findings and concerns presented in the reference [2], "Sewage Sludge Management in Germany".

An indicative conclusion from Ducey and Ro is that a heat treatment stage - for instance an HTC -vessel may be the adequate and suitable process to decompose even the cellfree DNA.

A full-scale HTC-facility operated in China is presented in [13]. The plant has been in operation for a few years and detail results are now available, demonstrating feasible performance. 


\subsection{The Hydrothermal Carbonization (HTC) Process as a Step for Phosphorus Recovery}

Recent studies on the possibilities to concentrate and extract phosphorus from the hydrochar indicates that more than $90 \%$ of the phosphorus is retained in the hydrochar, see [14].

In a study presented this spring (2019) Bigum and Widerberg in a master thesis the possibilities to extract phosphates from the hydrochar were made, see further [15]. The presented results confirmed previously found results done by leaching method, yielded, a $95.7 \%$ phosphorus recovery. However, around $80 \%$ of $\mathrm{Al}$ and $\mathrm{Fe}$ contained in hydrochar was collected in the phosphorus rich precipitate. Results obtained from the experimental investigation of sequential leaching and precipitation indicate that phosphorus recovery from sewage sludge hydrochar was most advantageous utilizing $0.1 \mathrm{M} \mathrm{HNO}_{3}$ (acidic leaching) and $\mathrm{pH}$ 13 (alkaline leaching). At these conditions 67\% phosphorus was recovered from the sewage sludge hydrochar. Levels of metal contaminants collected in the phosphorus rich precipitate was lower than at other conditions $8.5 \% \mathrm{Al}$ and $7.5 \% \mathrm{Fe}$.

Results obtained in this study suggest that phosphorus recovery from sewage sludge processed via hydrothermal carbonization could pose as a promising sewage sludge nutrient recycling method. Further development of this method could in the future offer an additional processing option among existing technologies aimed at phosphorus recovery from sewage sludge.

\section{Conclusions and Perspectives}

The current knowledge on municipal sludge as both a potential resource for carbon and phosphorus recovery is contributing to an increased interest to develop and refine technologies for the capture and reuse of these resources. As a matter of fact, the techniques presented are not at all new. However, new conditions with respect to environmental and sanitation concerns and far more stringent requirements will call for further both theoretical studies and engineering work, possibly to combine the techniques in different ways.

To summarize, the following is highlighted on the actual status with respect to the HTC-process:

(1) The process will incorporate both sludge stabilization and hygienization by convention;

(2) The option to recover both phosphorus and carbon as potential valuable raw materials;

(3) The process has good possibilities to combine with the classic anaerobic digestion process.

(4) The hydrochar would contain up to $90 \%$ of the inlet carbon content, as well as a similar level of phosphorus.

(5) The dewaterability of the concentrate is far more efficient by mechanical technology compared with conventional sludge streams. The concentration maybe up to 50 to $60 \% \mathrm{DS}$, as compared with conventional models reaching $25-35 \%$ DS.
(6) The process itself is theoretically exothermic, thus a potential for an additional energy recovery.

(7) Tests have demonstrated that by recycling the reject water to the anaerobic digester stage the methane gas production maybe increased by $20-30 \%$.

The important points that need further investigations are inter alia

(1) To further clarify the quality of reject water from the hydrochar, with respect to rest pollutants;

(2) To evaluate to what extent the HTC process may become a feasible way to disintegrate pharmaceutical remains found in municipal sludge.

(3) How to further enhance the ways to recover raw materials from the hydrochar, such as phosphorus and carbon.

Nethertheless, the process may allow for some very promising pathways within the future municipal sludge management.

\section{Acknowledgements}

This paper has been worked out thanks to very good contributions from several competent colleges: The associate professors of LTH, the Technical University of Lund, Sweden, Mr Michael Cimbritz, Mrs Åsa Davidsson. For the work on the development of the HTC process and the extraction of phosphorus Dr Eva Björkman and Mr Malte Lilliestråhle of Biokol Svenska $\mathrm{AB}$ have supplied with knowledge and process development. For the linguistic scrutinization of the text Mr Guy Taylor, Sweco International has done the needed corrections. Thank you all.

\section{References}

[1] Cimbritz, M., Davidsson, Å., Hey, G., Jonstrup, M., Åstrand, N. and Morling, S. (2017) "A critical study on the methane gas production in relation to an extended SRT (Solids Retention Time) in activated sludge".

[2] Ge. H. Q. Batstone, D. J and Keller. J. (2013)" Operating aerobic wastewater treatment at very short sludge ages enables treatment and energy recovery through anaerobic sludge digestion" Water Research, Vol. 47, 173-182.

[3] Carlsson. M. (2015). "When and why is Pre-Treatment of Substrates for Anaerobic Digestion Useful?" Doctoral Thesis, Luleå university of Technology, ISBN 978-91-7583-377-4.

[4] Wiechman, A., Dienemann, C., Kabbe, C., Brandt, S. and Vogel, Ines (2017) "Sewage Sludge Management in Germany", a report study to the German Umwelt Bundesamt.

[5] Kaschka, E. and Weyrer, S. (1999) "Phostrip Handbook", Phostrip Abwassertechnik GmbH, Fourth edition.

[6] Ttirici, M. M. editor (2013) "Sustainable Carbon Materials from Hydrothermal Processes”, John Wiley \& Sons Ltd, ISBN 978-1-119-97539-7 (hardback).

[7] Lucian, M. and Fiori, L. (2017) "Hydrothermal Carbonization of Waste Biomass: Process Design, Modeling, Energy Efficiency and Cost Analysis" Energies 2017, 10, 211, 18 pages. 
[8] Heilmann, S. M., Molde J. S., Timler, J. G., Wood, B. M., Mikula A. L., Vozhdayev G. V., Colosky E. C. Spokas K. A. and Valentas (2014) "Phosphorus Reclamation through a Hydro Thermal Carbonization process of Animal Manures" Environmental Science Technology 2014, 48, pp 10323 10329.

[9] Björkman, E. and Morling S. (2015) "Report for Kohtla-Järve, and some development issues" a presentation for the KohtlaJärve Vesi on sludge management questions within a technical project.

[10] Björkman, E and Lilliestråhle, M (2016) "Increased Yield of Biogas by Post Treatment of residual sludge", Report to the Swedish Energy Authority.

[11] Nilsson, E. (2017) “Anaerobic digestion trials with HTC process water", Master thesis presented at SLU, Swedish University of Agricultural Sciences, Uppsala, Sweden.
[12] Ducey, T. F. and Ro, K. S. (2019) "The use of hydrothermal carbonization for the removal of pathogens and antibiotic resistance genes from animal waste" USDA-ARS, Coastal Plain Soil, Water and Plant Research Center, Agricultural Research Service, 2611 West Lucas Street, Florence SC, USA.

[13] Buttmann, T. (2017) "Industrial Scale Plant for Sewage Sludge Treatment by Hydrothermal Carbonization in Jining/China and Phosphate Recovery by TerraNova Ultra HTC Process" www.european-biosolids.com.

[14] Björkman, E., Wirth, B. and Clemens, A. (2017) "Report to the Swedish Energy Authority within the Recovery project on determination of potential phosphorus recovery".

[15] Bigum, L. and Widerberg, R. (2019) Phosphorus Recovery from Sewage Sludge Hydrochar, Master Thesis at the Royal Institute of Technology (KTH), Stockholm. 